Original article

\title{
Phenotype of bone-marrow mononuclear cells before and after short-time precondition with erythropoietin from patients with ischemic heart failure
}

\author{
Alexander P. Lykov ${ }^{1,2}$, Olga V. Poveshchenko ${ }^{1,2}$, Alexander M. Cherniavsky ${ }^{1}$, Alexei V. Fomichev ${ }^{1}$ \\ Maria A. Surovtseva ${ }^{1,2}$, Natalia A. Bondarenko ${ }^{1,2}$, Irina I. Kim ${ }^{1,2}$, Yulia E. Kareva ${ }^{1}$, Alexandra R. Tarkova ${ }^{1}$ \\ ${ }^{1}$ Meshalkin National Medical Research Center, Novosibirsk, Russia \\ ${ }^{2}$ Research Institute of Clinical and Experimental Lymphology - Branch of the Institute of Cytology and Genetics, Novosibirsk, Russia
}

Received 6 July 2017, Revised 7 November 2017, Accepted 24 November 2017

(C) 2017, Lykov A.P., Poveshchenko O.V., Cherniavsky A.M., Fomichev A.V., Surovtseva M.A., Bondarenko N.A., Kim I.I., Kareva Y.E., Tarkova A.R.

(C) 2017, Russian Open Medical Journal

Abstract: Aim - To reveal the results of the condition of the bone marrow mononuclear cells (BM-MNCs) with erythropoietin (Epo).

Material and Methods - There were 30-ty patients with coronary artery disease (CAD) enrolled in this study during 2016-2017 years. 95\% were men. All were in angina NYHA class II-III. Hypertension presented in 90\%, peripheral atherosclerosis in $60 \%$. BM-MNCs were obtained by centrifugation of bone marrow aspirate on Ficoll-Paque, washed, and then preconditioned with Epo. Phenotype, cell cycle, cell death, proliferation, migration, and tube formation before, and after precondition BM-MNCs with Epo were done.

Results - In this study, we observed the presence in cellular graft of the hematopoietic stem cells (HSCs), and endothelial progenitor cells (EPCs) at the different stage of maturation/differentiation, and mesenchymal stem cells (MSCs). Precondition BM-MNCs with Epo increased number of HSCs carrying erythropoietin receptor (EpoR), and EPCs carrying CD184. Also, Epo detained CB34+ cells in a rest phase of cell cycle (G0G1). Condition media from BM-MNCs treated with Epo augment tube formation and wound healing by EA.hy 929.

Conclusion - Epo in vitro increased number of the stem cells carrying EpoR and CD184, and increased accumulation of CD34+ cell in G0G1 phase of cell cycle, and induced production of proangiogenic factor by BM-MNCs. Further investigation is needed to assess the type of cytokines produced by BM-MNCs after condition with Epo.

Keywords: coronary artery disease, erythropoietin, erythropoietin receptor, bone marrow mononuclear cells, phenotype, apoptosis, cell cycle

Cite as Lykov AP, Poveshchenko OV, Cherniavsky AM, Fomichev AV, Surovtseva MA, Bondarenko NA, Kim II, Kareva YE, Tarkova AR. Phenotype of bonemarrow mononuclear cells before and after short-time precondition with erythropoietin from patients with ischemic heart failure. Russian Open Medical Journal 2018; 7: e0202.

Correspondence to Alexander P. Lykov. Address \#1: Meshalkin National Medical Research Center, Rechkunovskaya Str., 15, Novosibirsk, 630055, Russia. Address \#2: Research Institute of Clinical and Experimental Lymphology - Branch of the Institute of Cytology and Genetics, Timakova Str., 2, Novosibirsk, 630090, Russia.E-mail: aplykov2@mail.ru.

\section{Introduction}

Stem cell therapy in ischemic diseases has been regarded as a new method to repair ischemic tissues and promote neovascularization. Coronary artery disease (CAD) remains a major cause of morbidity and mortality [1-2]. Angiogenesis play a crucial role in regeneration of ischemic tissues. Different types of stem cells may be used for therapeutic neovascularization, including endothelial progenitor cells (EPCS), which play an important role in neovascularization, and in regeneration of injurie vessels [2-3]. Also, mesenchymal stem cells (MSCs) can be used for vessel repair, because they can migrate into damaged tissue and produced paracrine growth factors [2-3]. Stem cells therapy for improvement myocardial function and perfusion is perspective method in patients with CAD [2-4]. Bone marrow progenitor cells are able to migrate in ischemia zone, and stimulate proliferation of the resident progenitor cells, and differentiation, and migration in a damage zone, and reduce an ischemia zone through formation of new vessels [2-4]. Those effects of progenitor cells in the majority are caused by action through production of a wide range of paracrine growth factors [5]. Efficacy of stem cells therapy depends on circumstances in region of myocardium where cells were implanted. So, oxidative stress reduced survival rate of stem cells [6]. Early, we reported that erythropoietin abolished negative effect of the hypoxia on bone marrow mesenchymal stem cells proliferation [7].

Aim of study: to assess the effects of short-term precondition of bone marrow mononuclear cells (BM-MNCs) with erythropoietin (Epo) on the phenotype of stem cells and survival rate of the BM-MNCs under hypoxia-condition in vitro.

\section{Material and Methods}

\section{Patients}

Thirty samples of BM-MNCs for evaluation of anti-apoptotic effects of Epo in vitro were performed at the Meshalkin National 
Medical Research Center (Novosibirsk, Russia) as isolated procedure for patients with CAD.

The study design was randomized and uncontrolled. All patients were randomized in January 2016 - June 2017 period. Informed consent was obtained for all patients before participation in the study.

Patients had to be at least 45 years old, suffering from coronary artery disease (CAD), and receiving constant state-of-theart pharmacotherapy for at least 3 months prior to enrolment. $95 \%$ were men. All were in angina NYHA class II-III. Hypertension was presented in $90 \%$ of patients, peripheral atherosclerosis in $60 \%$.

The inclusion criteria were as follows:

i) age $\geq 45$ and $<75$ years,

ii) presence of coronary artery lesions,

iii) chronic ischemia heart failure (IHF), without option to revascularization,

iv) myocardial infarction within previous 12 months,

v) New York Heart Association (NYHA) functional class II-III within last 6 months,

vi) systolic dysfunction with LVEF $\leq 35 \%$,

vii) fixed perfusion defect on Tc-99m technetril singlephoton emission computed tomography (SPECT).

The exclusion criteria comprised the following factors:

i) eligibility for percutaneous coronary intervention,

ii) eligibility for coronary artery bypass grafting,

iii) previous valve surgery,

iv) surgical remodeling of the left ventricle or cardiac resynchronization therapy,

v) hemorrhagic symptoms,

vi) severe renal and liver dysfunction,

vii) malignancy.

Patients who meet eligibility criteria will be scheduled for bone marrow harvest.

\section{Study design}

Bone marrow samples $(50 \mathrm{~mL})$ were obtained by aspiration under local anesthesia from the posterior iliac crest, placed in sterile tubes containing preserve-free lithium heparin $(25,000 \mathrm{U}$; Gedeon Richter Ltd., Hungary) from all patients.

BM-MNCs were quantified using the following approach: ethylenediaminetetraacetic acid (EDTA) collection tubes were transported on wet ice into the cellular technology laboratory in Research Institute of Clinical and Experimental Lymphology Branch of the Institute of Cytology and Genetics (Novosibirsk, Russia) and preceded within 2 to 3 hours.

Bone marrow aspirates were diluted with phosphate buffered saline (PBS) (Oxoid Limited Dasingstoke, Hampshire, England), and BM-MNCs were isolated by density gradient centrifugation with Ficoll-Paque (800g, 20 minutes, without brake; BioloT, Russia). The BM-MNCs were washed three times with $50 \mathrm{~mL}$ of PBS (800g), counted, and viability testing was performed with trypan blue exclusion ( $\geq 95 \%$ ), and used for the experiments.

The $10^{6} \mathrm{BM}-\mathrm{MNCs} / \mathrm{cm}^{2}$ was cultured in PBS supplemented completed with $10 \%$ autologous serum and Epo $(33.4 \mathrm{IU} / \mathrm{mL}$; Recormon, Roche Diagnostic, Germany) in T75 tissues flasks (TPP)
(Switzerland) during 60 minutes in $\mathrm{CO}_{2}$-incubator. After precondition BM-MNCs were twice washed with PBS.

\section{Antibodies and staining procedure for fluorescence-activated cell sorter analysis}

The following antibodies were conjugated with fluorescein isothiocyanate (FITC), phycoerythrin (PE), or allophycocyanin (APC): anti-CD45 as a pan-leukocyte marker, anti-CD34 as a hematopoietic progenitor marker, anti-CD31 as a platelet endothelial cell adhesion molecule-1, anti-CD184 as a C-X-C chemokine receptor type 4 , anti-CD73 as a 5'-nucleotidase, antiCD90 as a Thy-1, anti-CD105 as a Endoglin, anti-CD131 as a Cytokine receptor common subunit $\beta$, anti-CD144 as a Cadherin 5 , type 2 or VE-cadherin (vascular endothelial cadherin) from Becton Dickinson, anti-CD133 as a prominin-1, anti-KDR (kinase insert domain receptor) as a vascular endothelial growth factor (VEGF) receptor 2 from Abcam, and anti-EpoR as a erythropoietin receptor (EpoR) from Sigma. Sample suspensions were adjusted to $10^{6}$ cells $/ \mathrm{mL}$ and incubated on ice with the appropriate antibody for $20 \mathrm{~min}$, washed twice, and were re-suspended in $0.5 \mathrm{~mL} 1 \%$ bovine serum albumin in PBS. Dead cells were excluded by electronic gating and 30,000 gating events were analyzed for each sample. Three-color immunofluorescence analysis was used for the identification of BM-MNCs. Data acquisition and analyses were performed on a fluorescence-activated cell sorter Cantoll with Diva software (BD Bioscience, San Jose, CA, USA).

\section{Cell cycle analyses}

Cell cycle distribution and measurement were performed by flow cytometry. To this order, $1 \times 10^{6} \mathrm{BM}-\mathrm{MNCs} / \mathrm{mL}$ before and after precondition with Epo $(33.4 \mathrm{IU} / \mathrm{mL}$; Recormon, Roche Diagnostic, Germany) were washed with cold PBS and fixed in $70 \%$ ethanol $\left(-20^{\circ} \mathrm{C}\right)$ at $4^{\circ} \mathrm{C}$. After 2 hours, fixed cells were pelleted and stained with Propidium iodide $(20 \mu \mathrm{g} / \mathrm{mL})$ in the presence of Ribonuclease (RNAse) A (100 $\mathrm{mg} / \mathrm{mL}$; Sigma-Aldrich, Germany) for 30 minutes at $37^{\circ} \mathrm{C}$, and about $10^{4}$ cells were analyzed using a fluorescence-activated cell sorter Canto II and data were analyzed by using Diva software.

\section{Determination of cell death}

The apoptosis assay was performed using an Annexin V-FITC/PI Apoptosis Detection kit (BD Bioscience, San Diego, CA, USA). The untreated and treated with Epo $(33.4 \mathrm{IU} / \mathrm{mL}) \mathrm{BM}-\mathrm{MNCs}$ were washed with Annexin binding buffer and centrifuged three times at $800 \mathrm{~g}$ for 5 minutes. Next, $100 \mu \mathrm{L}$ of binding buffer were added and incubated with $5 \mu \mathrm{L}$ of Annexin V-FITC and $5 \mu \mathrm{L}$ of Propidium iodide for 20 minutes in the dark at room temperature. After a last step, the samples were analyzed using a flow cytometer (FACS Canto II, BD Bioscience, San Jose, CA, USA) and data was analyzed by using Diva software. Alive cells grouped in the lower left part of the panel, early apoptotic cells grouped in the lower right part of the panel, and late apoptotic cells grouped in the higher right part of the panel.

\section{Cell proliferation MTt assay}

BM-MNCs were cultured in a 96-well plate at a density of $2 \times 10^{5}$ cells/well with Concanavalin A $(10 \mu \mathrm{g} / \mathrm{mL}$; Sigma-Aldrich, Germany), Phytohemagglutinin A $(10 \mu \mathrm{g} / \mathrm{mL}$; Sigma-Aldrich, Germany), Lipopolysaccharide ( $1 \mu \mathrm{g} / \mathrm{mL}$; Sigma-Aldrich, Germany), 
Epo (33.4 IU/mL), VEGF (10 ng/mL; Sigma-Aldrich, Germany), and $\mathrm{H}_{2} \mathrm{O}_{2}(1,3$, and $5 \mathrm{mM}$; Sigma-Aldrich, Germany) in Dulbecco's Modified Eagle's Medium (DMEM) (BioloT, Russia) supplemented by heat-inactivated $10 \%$ fetal calf serum (FCS) (Sigma-Aldrich, Germany), $0.3 \mathrm{mg} / \mathrm{mL}$ L-glutamine (Sigma-Aldrich, Germany), 5 mM HEPES (4-[2-hydroxyethyl]-1-piperazineethanesulfonic acid) buffer (Sigma-Aldrich, Germany), and $80 \mu \mathrm{g} / \mathrm{mL}$ of gentamycin (Sigma-Aldrich, Germany) during 72 hours in $\mathrm{CO}_{2}$-incubator, then cells were supplemented with fresh medium containing $5 \mathrm{mg} / \mathrm{mL}$ MTT (3-[4,5-dimethylthiazol-2-yl]-2,5-diphenyl-tetrazolium bromide) (Sigma-Aldrich, Germany) and incubated for 4 hours at $37^{\circ} \mathrm{C}$. The formazan in viable cells was dissolved with $100 \mu \mathrm{L}$ of dimethyl sulfoxide and determined by reading optical densities (OD) in microplate reader (Stat Fax 2100, Florida, USA) at an absorption wave length of $570 \mathrm{~nm}$.

\section{Conditioned media}

Conditioned media from $2 \times 10^{5}$ cells/well of BM-MNCs incubated in a 96-well plate in DMEM supplemented by $10 \% \mathrm{FCS}, 2$ $\mathrm{mM}$ L-glutamine, and antibiotics, and Epo $(33.4 \mathrm{lU} / \mathrm{mL})$ was collected 72 hours later, aliquoted and storage at $-70^{\circ} \mathrm{C}$ before using in testing in vitro.

\section{Scratch-wound migration assays}

EA.hy 929 cells (gifted by Dr. C.J. Edgel, Caroline University, USA) were grown to $80-90 \%$ confluence in a 96-well plate, and incubated in medium containing $1 \%$ FCS overnight. EA.hy 929 monolayer were scratched with a $200 \mu \mathrm{L}$ pipette tip, washed to remove debris and cultured in $100 \mu \mathrm{L}$ of DMEM containing $10 \%$ FCS (positive control), in mixture of $70 \%$ DMEM and $30 \%$ of conditioned media from BM-MNCs growth in the presence or absence of Epo (experimental wells), and in $100 \mu \mathrm{L}$ of DMEM with $0 \% \mathrm{FCS}$ (negative control), the incubated at $37^{\circ} \mathrm{C}$ in $\mathrm{CO}_{2}$-incubator for 24 hours. Images were observed using an inverted contrast microscope (Zeiss, Germany).

\section{Tube formation assay}

The formation of vascular-like structures (tube formation) by EA.hy 929 cells was assessed on In vitro angiogenesis assay kit (Abcam, USA). EA.hy 929 cells were seeded on Matrigel-coated 96well plates at $2 \times 10^{4}$ cells/well in $100 \mu \mathrm{L}$ of DMEM containing $10 \%$ FCS (positive control), in mixture of $70 \%$ DMEM and $30 \%$ of conditioned media from BM-MNCs growth in the presence or absence of Epo (experimental wells), and in $100 \mu \mathrm{L}$ of DMEM with $0 \% \mathrm{FCS}$ (negative control), the incubated at $37^{\circ} \mathrm{C}$ in $\mathrm{CO}_{2}$-incubator for 24 hours. Capillary-like structure formation images were observed using an inverted contrast microscope (Zeiss, Germany).

\section{Statistical analysis}

The obtained results were processed by statistical software package Statistica 10.0. Data presented as median with lower and upper quartiles - Me (LQ, UQ). We use Mann-Whitney $U$ test for pairwise comparisons of studying data. Statistical significance was assumed at a value of $p<0.05$. Correlations analysis was performed by Spearman rank correlation.
Table 1. Heterogeneity of bone marrow mononuclear cells in patients with CAD

\begin{tabular}{|c|c|}
\hline Variable & Number $(n=30)$ \\
\hline \multicolumn{2}{|c|}{ Hematopoietic stem cells } \\
\hline CD45+/CD34- & $26.0(26.0,44.2)$ \\
\hline CD45+/CD184+ & $16.0(5.4,17.7)$ \\
\hline CD45+/EpoR+ & $0.7(0.4,1.0)$ \\
\hline
\end{tabular}

CD45+/EpoR+ Endothelial progenitor cells

CD34+/CD45

$0.3(0.2,0.6)$

CD34+/CD31+

$0.7(0.4,1.0)$

$\mathrm{CD} 34+/ \mathrm{KDR}+$

$1.0(0.7,1.9)$

CD34+/CD131+

$1.0(0.2,2.3)$

CD34+/CD133+

$1.0(0.6,1.2)$

$\mathrm{CD} 34+/ \mathrm{CD} 144+$

$0.2(0.2,0.2)$

CD34+/CD184+

$2.0(1.0,3.4)$

CD34+/EpoR+

$0.7(0.4,1.0)$

CD31+/CD184+ $2.0(2.0,7.5)$ Mesenchymal stem cells

$\mathrm{CD} 90+/ \mathrm{CD} 73+$

$0.9(0.4,2.1)$
$0.4(0.4,1.0)$

$\mathrm{CD} 90+/ \mathrm{CD} 105+$

CD73+/CD105+

$2.0(1.1,5.8)$

Data are presented as median with lower and upper quartiles on percentage of BM-MNCs - Me (LQ, UQ).

BM-MNCs, bone marrow mononuclear cells; CAD, coronary artery disease; $C D$, cluster of differentiation; EpoR, erythropoietin receptor; KDR, vessel endothelial growth factor receptor II type.

Results

\section{Heterogeneous BM-MNCS phenotypes}

There were significant higher number of hematopoietic stem cells (HSCS), endothelial progenitor cells (EPCS), and mesenchymal stem cells (MSCs) among BM-MNCs (Table 1). The HSCs in patients with $C A D$ were predominantly composed of higher number of CD45+/CD43- (>30\%), CD45+/CD184+ (>16\%), and CD45+/EpoR+ (>3\%) cells.

Among EPCs were established cells expressing CD34+/CD45$(>0.6 \%), \quad \mathrm{CD} 34+/ \mathrm{CD} 31+\quad(>0.9 \%), \mathrm{CD} 34+/ \mathrm{KDR}+\quad(>1.25 \%)$, CD34+/CD133+ >0.95\%), CD34+/CD144+ (>0.2\%), CD34+/CD131+ $(>1.15 \%), \mathrm{CD} 34+/ \mathrm{CD} 184+(>2.6 \%), \mathrm{CD} 34+/ \mathrm{EpoR}+(>0.85 \%)$, and CD31+/CD184+ (>5.5\%) cells.

MSCs contained cells expressed CD90+/CD73+ (>1.3\%), CD90+/CD105+ (>0.9\%), and CD73+/CD105+ (>3.7\%).

These findings indicated that BM-MNCs from patients with CAD contained heterogeneous stem cells populations.

Comparison of baseline morphofunctional properties of BMMNCs treated with and without erythropoietin

Table 2 presents the baseline variables of Morphofunctional properties of BM-MNCs in both groups. In this study, the complete BM-MNCs count before and after Epo treatment were determined the time courses of levels of EPCs (CD31/CD34 cells, CD34/CD133 cells, CD34/KDR cells, CD31/CD184 cells, CD34/CD184 cells, CD34/EpoR cells, and CD34/CD131 cells) in patients with CAD. The results showed that the levels of EPCs expressed CD34+/CD133+ significantly decreased, whereas the levels of EPCS bearing CD31+/CD184+ surface marker significantly increased after treatment with Epo. Also, we observed increased count of HSCs that bearing on surface CD45+/EpoR+ marker. 
Table 2. Effect of treatment with erythropoietin on BM-MNCs properties

\begin{tabular}{|c|c|c|c|}
\hline Variable & Group $1(n=30)$ & Group $2(n=30)$ & p-level \\
\hline \multicolumn{4}{|l|}{ Phenotype: } \\
\hline CD45+/EpoR+ & $0.7(0.4,1.0)$ & $5.0(1.8,17.0)$ & 0.005 \\
\hline CD34+/CD31+ & $0.7(0.4,1.0)$ & $1.0(0.5,1.0)$ & 0.320 \\
\hline CD34+/CD133+ & $1.0(0.6,1.2)$ & $0.7(0.1,0.7)$ & 0.026 \\
\hline CD34+/KDR+ & $1.0(0.7,1.9)$ & $0.3(0.1,2.5)$ & 0.850 \\
\hline CD31+/CD184+ & $2.0(2.0,7.5)$ & $10.0(5.0,11.0)$ & 0.007 \\
\hline CD34+/CD184+ & $2.0(1.0,3.4)$ & $1.7(0.4,2.0)$ & 0.230 \\
\hline CD34+/EpoR+ & $0.7(0.4,1.0)$ & $0.5(0.4,0.7)$ & 0.160 \\
\hline CD34+/CD131+ & $1.0(0.2,2.3)$ & $0.3(0.2,1.7)$ & 0.650 \\
\hline \multicolumn{4}{|c|}{ Cell cycle distribution among CD34+ cells: } \\
\hline Sub G0G1 & $5.0(5.0,5.0)$ & $6.0(6.0,6.0)$ & 0.013 \\
\hline G0G1 & $78.0(78.0,78.0)$ & $85.0(85.0,85.0)$ & 0.003 \\
\hline $\mathrm{G} 2 / \mathrm{M}$ & $13.0(13.0,13.0)$ & $7.0(7.0,7.0)$ & $<0.001$ \\
\hline $\mathrm{S}$ & $3.0(3.0,3.0)$ & $1.0(1.0,1.0)$ & $<0.001$ \\
\hline \multicolumn{4}{|c|}{ Apoptosis among CD34+ cells: } \\
\hline Early apoptosis & $5.4(1.9,10.0)$ & $4.0(0.9,5.0)$ & 0.150 \\
\hline Apoptosis & $0.4(0.1,3.1)$ & $2.0(0.5,2.1)$ & 0.210 \\
\hline Necrosis & $0.8(0.3,1.1)$ & $1.0(0.3,1.0)$ & 0.970 \\
\hline \multicolumn{4}{|l|}{ Proliferation: } \\
\hline Spontaneous & $0.66(0.56,0.68)$ & $0.40(0.40,0.45)$ & 0.001 \\
\hline ConA $(10 \mu \mathrm{g} / \mathrm{mL})$ & $0.57(0.55,0.59)$ & $0.36(0.36,0.46)$ & 0.013 \\
\hline PHA A $(10 \mu \mathrm{g} / \mathrm{mL})$ & $0.60(0.60,0.67)$ & $0.45(0.36,0.46)$ & $<0.001$ \\
\hline LPS $(1 \mu \mathrm{g} / \mathrm{mL})$ & $0.70(0.66,0,70)$ & $0.50(0.44,0.50)$ & $<0.001$ \\
\hline VEGF (10 ng/mL) & $0.69(0.64,0.70)$ & $0.39(0.32,0.39)$ & $<0.001$ \\
\hline Epo (33.4 IU/mL) & $0.70(0.54,0.82)$ & $0.50(0.49,0.53)$ & 0.007 \\
\hline $1 \mathrm{mM} \mathrm{H}_{2} \mathrm{O}_{2}$ & $0.70(0.57,0.76)$ & $0.36(0.32,0.36)$ & $<0.001$ \\
\hline $3 \mathrm{mM} \mathrm{H}_{2} \mathrm{O}_{2}$ & $0.60(0.51,0.64)$ & $0.40(0.30,0.42)$ & $<0.001$ \\
\hline $5 \mathrm{mM} \mathrm{H}_{2} \mathrm{O}_{2}$ & $0.57(0.33,0.57)$ & $0.38(0.34,0.38)$ & 0.048 \\
\hline
\end{tabular}

Group 1, without erythropoietin treatment; Group 2, with erythropoietin treatment.

Data are presented as Me (LQ, UQ) on percentage of BM-MNCs and as $\mathrm{Me}(\mathrm{LQ}, \mathrm{UQ})$ on optical density of proliferation.

ConA, Concanavalin A; Epo, erythropoietin; EpoR, erythropoietin receptor; LPS, lipopolysaccharide; PHA-A, Phytohemagglutinin A; VEGF, vascular endothelial growth factor

Moreover, short-time Epo treatment of BM-MNCs influenced on the cell cycle distribution among CD34+ cells in patients with CAD. So, significantly increased numbers of CD34+ cells in G0G1, and in subGOG1 (apoptotic cells) phase of cell cycle, whereas significantly decreased numbers of CD34+ cells in $\mathrm{G} 2 / \mathrm{M}$, and $\mathrm{S}$ phase of cell cycle. By using the Annexin V-FITC/PI Apoptosis Detection kit we have not found anything significant differences in the number of CD34+ cells in apoptosis after Epo treatment comparing with baseline number.

Also, we observed, that mitogen or antigen stimulus did not activate BM-MNCs proliferation, whereas hydrogenium peroxide in dose-dependent manner decreased proliferation of BM-MNCs. Precondition of BM-MNCs with Epo significantly reduced proliferation comparing with non-treated BM-MNCs $(p<0.05)$.

These findings implicate that this short-time treatment of BMMNCs with erythropoietin enhanced the count of CD31+/CD184+ EPCs and CD45+/EpoR+ HSCs, arrest CD34+ in G0G1, and no have stimulated proliferative activity of BM-MNCs.

\section{Paracrine effect of BM-MNCs on EA.hy 929 formation of} vascular-like structures and wound healing

BM-MNCs can directly take part in angiogenesis, whereas paracrine effect may also be important. We analyses the conditioned media of Epo treated BM-MNCs cultured 1 hour. A Matrigel tube formation assay and wound closure test were used to check whether the conditioned media of Epo treated BM-MNCs can induce vasculogenesis and EPCs migration. Compared with the negative control (culture media with 0\% FCS) and positive control (culture media with $10 \% \mathrm{FCS}$ ), $30 \%$ (v/v) of conditioned media from Epo treated BM-MNCs had a significantly enhanced formation of capillary-like structures and wound healing by EA.hy 929 (Figure 1).

These finding indicate that Epo therapy of BM-MNCs possess increased production of cytokines and growth factors that can promote proliferation and vasculogenesis by mature EPCs.

Correlation between BM-MNCS subsets and age and NYHA of patients with CAD

We showed strong correlation between number of CD34+/CD133+, and number of CD34+/EpoR+ cells with age of patients $(R=0.52$ and $R=0.49, p<0.05)$. Between number of CD45+/EpoR+, and number of CD34+/EpoR+ cells, and NYHA shown negative correlation ( $R=-0.49$ and $R=-0.43, p<0.05$ ).

\section{Discussion}

Through this study we have showed the beneficial effect of in vitro Epo treatment to increase the vasculogenic potential of human bone marrow stem cells. By Epo treatment BM-MNCs increased count of EPCs with CD31+/CD184+ phenotype, increased a count of CD34+ cells in GOG1 phase of cell cycle, increased vasculogenic effect of conditioned media from Epo treated BMMNCs on tube formation by EA.hy 929.

These findings strongly suggest that in vitro Epo treatment of BM-MNCs can be a feasible and effective method to augment the efficacy of BM-MNCs stem cells therapy for patients with CAD.

Ischemic heart failure (IHF) is an important cause of morbidity and mortality [1-2]. The main reason of IHF development are myocardium infarct, because structural remodeling of a myocardium is associated with inflammation, formation of scar, and development of interstitial fibrosis in peri-infarct zone and remodeling of blood supply of a myocardium [8]. Bone marrow mononuclear cells contain EPCs and MSCs valuable in stem cell therapy to enhanced postischemic neovascularization [9-11].

Numerous clinical trials have previously investigated the clinical outcomes in patients after myocardium infarction and reported significant efficacy in improving contractility and reducing infarct scar $[2-4,8,10-11]$. But the problem was the limited efficacy: improvement of levft-ventrcular ejection fraction and reduction of infarct size, viability of stem cells. Under this situation, precondition of the adult stem cells before implantation would be a very feasible and safe way to augment the therapeutic efficacy.

Epo, cytokine that controlled erythropoiesis, also appears to have pleiotropic effects, such as anti-ischemic and anti-apoptotic properties, promotion of neovascularization, mobilization of EPCS, and enhancement of angiogenesis [12].

First of all, we established that in bone marrow of patients with CAD present three main stem cells populations (HSC, EPCs and MSCs). Moreover, BM-MNCs presented a higher number of 'early', and a lower number of 'late' EPCs (CD34-/CD133+, and CD34+/CD133- cells, respectively). Also, in BM-MNCs from patients with CAD presented 'mature' EPCS (CD34+/KDR+, and CD34+/CD31+ cells). Moreover, BM-MNCs from patients with CAD is characterized as a high proliferating cells, because a $12 \%$ of CD34+ cells are in G2/M phase of cell cycle and spontaneous proliferation measured by $\mathrm{MTT}$ test were $\mathrm{OD}=0.66$. Moreover, we observed that among CD34+ BM-MNCs very low number of cells is apoptotic cells. 

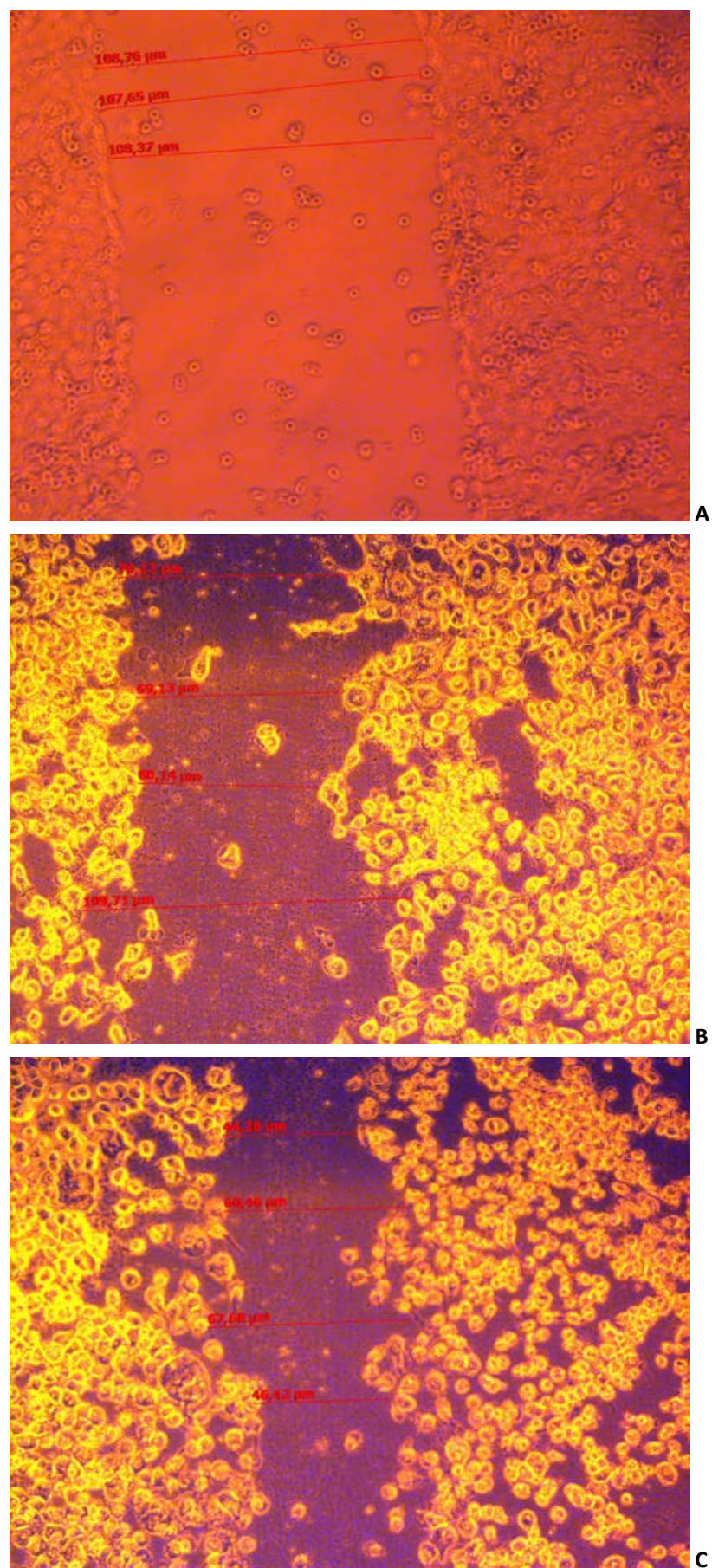

Figure 1 (part 1). Effect of condition media from BM-MNCs treated with Erythropoietin on wound healing and vessel-like structure formation by EA.hy 929. A - micrograph of a wound closure in media without growth factors at $\mathbf{2 4}$ hours (negative control). B - micrograph of a wound closure in media with $10 \%$ FSC at 24 hours (positive control). C - micrograph of a wound closure in media with $30 \%(\mathrm{v} / \mathrm{v})$ conditioned media from Erythropoietin treated BM-MNCs at 24 hours.
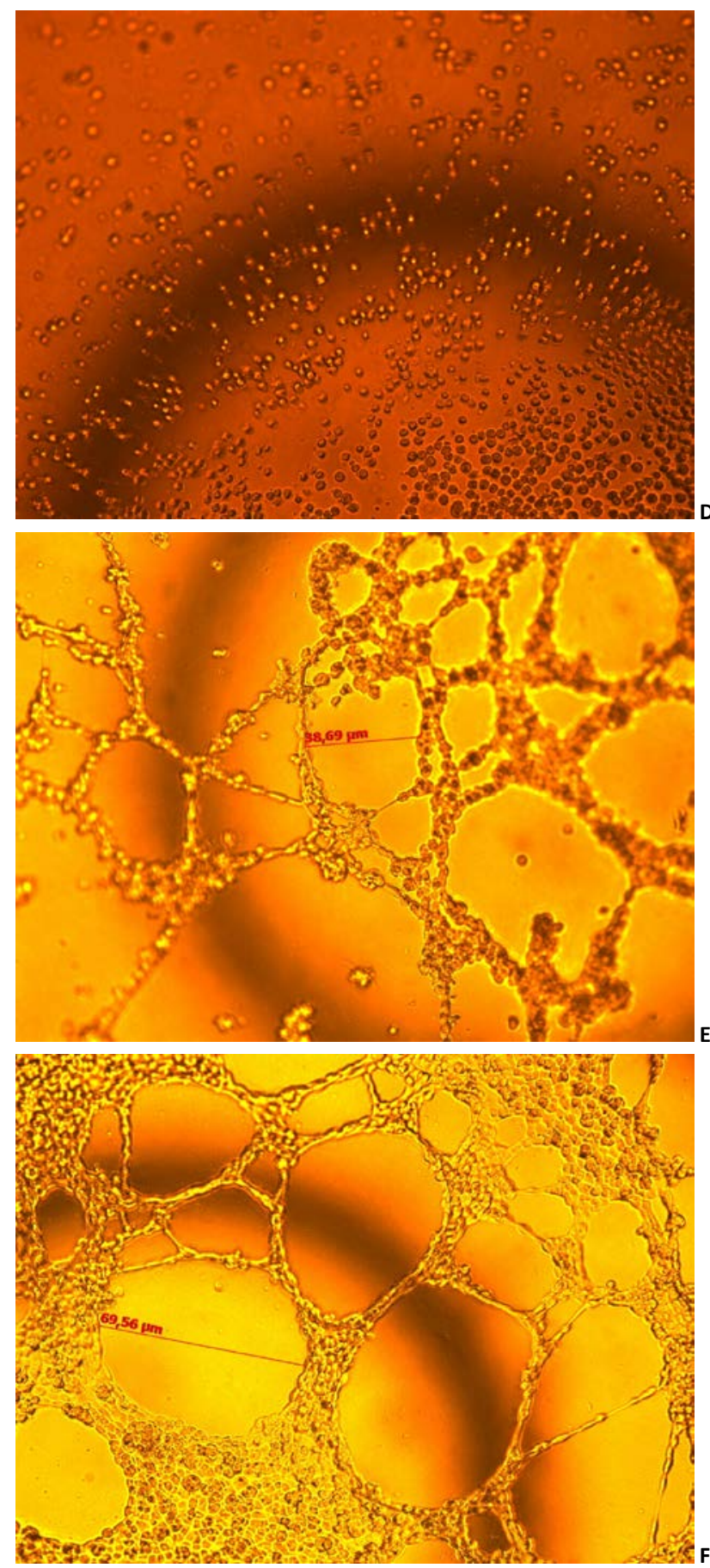

Figure 1 (part 2). Effect of condition media from BM-MNCs treated with Erythropoietin on wound healing and vessel-like structure formation by EA.hy 929. D - micrograph of a vessel-like formation by EA.hy 929 at 0 hour. E - micrograph of a vessel-like formation by EA.hy 929 in presence of $30 \%(\mathrm{v} / \mathrm{v})$ conditioned media from BM-MNCs with Erythropoietin 0 $\mathrm{IU} / \mathrm{mL}$ at 24 hours (negative control). $\mathrm{F}$ - micrograph of a vessel-like formation by EA.hy 929 in presence of $30 \%(\mathrm{v} / \mathrm{v})$ conditioned media from BM-MNCs with Erythropoietin $33.4 \mathrm{IU} / \mathrm{mL}$ at 24 hours. There was not found a significant differs in wound healing and vessel-like structure formation by EA.hy 929 in the presence of $10 \%$ FCs or $30 \%(v / v)$ of conditioned media from Erythropoietin treated BM-MNCs. 
Ahmed and coworkers (2015), also Hur and coworkers (2004) demonstrated that EPCs expressed CD34 or VEGFR-2(KDR), and EPCs, which carried both surface markers (CD34+/KDR+EPCs) is an independent predictor of clinical performance at cardiovascular pathology [13-14].

About $1 \%$ of BM-MNCs were positive for EpoR and these cells were used to evaluate the specific effects of Epo treatment through its receptor. Epo treated BM-MNCs show increases of HSCs bearing EpoR (increased in a 6.87-fold). Epo treatment also induced CD34+/CD133+ - EPCs decrease (on 30\%) and increase CD31+/CD184+ ("homing-receptor") - EPCs (in a 5-fold). Epo treatment also possess to accumulation of CD34+ cells in GOG1 phase of cell cycle (on 8.97\%). Epo treated BM-MNCs produced angiogenic factors, because addition of $30 \%(\mathrm{v} / \mathrm{v})$ of the conditioned media from Epo treated BM-MNCs augment capillarylike structure formation by EA.hy 929 , hybridoma cell line with "mature" EPCs phenotype properties.

Bone marrow cells can migrate from niches into blood stream through "homing" involve CXCR-4 (CD184), a specific receptor for the SDF-1/CXCL12, and CD144 to engraftment onto target organs, include ischemic tissues [15]. The results of presented study show that a large number of HSCS and EPCs expressed CD184, whereas CD144 expressed only on $0.3 \%$ of EPCs. Moreover, Epo treatment of BM-MNCs increased a count of EPCs co-expressed CD31 and CD184 surface markers.

It is well known, that EpoR expressed on surface not only of erythroid progenitor cells, but also on other type of cells [16-19]. Epo maintains survival of different type of cells through interaction with EpoR [16-17]. Epo binding with EpoR alone or in cooperation with CD131, and possess cytoprotective effect [19].

Bennis and coworkers (2012) demonstrated that Epo in dosage $5 \mathrm{IU} / \mathrm{mL}$ stimulate proliferative potential, migration, tubuleformation capacity, closure of wound made in monolayer of EPCs, and increased resistance of EPCs to oxidation stress [19]. The unfavorable microenvironment present in the ischemic tissue might impair the effectiveness of stem cell transplantation. Additionally, the results of presented study shown that Epo treatment of BM-MNCs prevent from oxidative stress (proliferative activity of Epo treated BM-MNCs in the presence of $\mathrm{H}_{2} \mathrm{O}_{2}$ ).

Kang et al. [18] demonstrated that treatment of bone marrow stem cells with Epo increased the expression of pro-angiogenic factors, include Interleukin-8 (IL-8), and IL-10, and basic fibroblast growth factor (bFGF), and platelet-derived growth factor (PDGF), and matrix metallopeptidase 9 (MMP-9), and levels of adhesion molecule such as integrin.

Taken together, the presented study demonstrated that Epo has the potential to augment regenerative effect of BM-MNCs.

\section{Conclusion}

In this paper, we present an in vitro model of BM-MNCs Epo priming augmented vasculogenic potential. Bone marrow cells from patient with CAD are characterized by presence of heterogeneous stem cells subsets (HSCs, EPCs, and MSCs) with a higher proliferation activity, and formation of vascular-like structures capacity. Treatment BM-MNCs with Epo possess accumulation of CD34+ cells in G0G1 phase of cell cycle and increased a count of CD31+/CD184+ EPCs.

\section{Acknowledgments} English.

The authors thank Ekaterina A. Lykova for her helping in translation on

\section{Funding}

This study received financial support of Russian Scientific Fond, Grant No. 16-15-00057.

\section{Conflict of interests}

Authors declare no conflict of interest.

\section{Ethical approval}

All procedures performed in studies involving human participants were in accordance with the ethical standards of the Ethics Review Board of the Meshalkin National Medical Research Center (Novosibirsk, Russia) and with the 1964 Helsinki declaration and its later amendments or comparable ethical standards.

\section{References}

1. Pasha Z, Wang $Y$, Sheikh R, Zhang D, Zhao T, Ashraf M. Preconditioning enhances cell survival and differentiation of stem cells during transplantation in infarcted myocardium. Cardiovasc Res 2008; 77: 134-142. https://doi.org/10.1093/cvr/cvm025.

2. Fisher SA, Doree C, Brunskill SJ, Mathur A, Martin-Rendon E. Bone marrow stem cell treatment for ischemic heart disease in patients with no option of revascularization: a systematic review and meta-analysis. PLOS ONE 2013; 8(6), e64669. https://doi.org/10.1371/journal.pone.006.

3. Vrtovec B, Poglajen G, Haddad F. Stem cell therapy in patients with heart failure. Methodist Debakey Cardiovasc J 2013; 9(1): 6-10. https://www.ncbi.nlm.nih.gov/pubmed/23518819.

4. Cogle CR, Wise E, Meacham AM, Zierold C, Traverse JH, Henry TD, et al. Detailed analysis of bone marrow from patients with ischemic heart disease and left ventricular dysfunction: BM CD34, CD11b, and clonogenic capacity as biomarkers for clinical outcomes. Circ Res 2014; 115: 867-874. https://doi.org/10.1161/CIRCRESAHA.115.304353.

5. Lykov AP, Bondarenko NA, Sakhno LV, Shevela EY, Poveschenko OV, Kim II, et al. The impact of secretory factors endothelial cells on the functional activity of human multipotent mesenchymal stromal cells. Fundamental Research 2014; 4(2): 296-301. Russian. https://elibrary.ry/item.asp?id=21379899.

6. $\mathrm{Hu} \mathrm{R}$, Cheng $\mathrm{Y}$, Jing $\mathrm{H}, \mathrm{Wu} \mathrm{H}$. Erythropoietin promotes the protective properties of transplanted endothelial progenitor cells against acute lung injury via PI3K/Akt pathway. Shock 2014; 42(4): 327-336. https://doi.org/10.1097/SHK.0000000000000216.

7. Lykov AP, Nikonorova YuV, Bondarenko NA, Poveshchenko OV, Kim II, Poveshchenko AF, et al. Proliferation, migration, and production of nitric oxide by bone marrow multipotent mesenchymal stromal cells from wistar rats in hypoxia and hyperglycemia. Bull Exp Biol Med 2015; 159(4): 443-445. https://doi.org/10.1007/s10517-015-2986-6.

8. Park JH, Yoon JY, Ko SM, Jin SA, Kim JH, Cho $\mathrm{CH}$, et al. Endothelial progenitor cell transplantation decreases lymphangiogenesis and adverse myocardial remodeling in a mouse model of acute myocardial infarction. Exp Mol Med 2011; 43(8): 479-485. https://doi.org/10.3858/emm.2011.43.8.054.

9. Wang $\mathrm{QR}$, Wang $\mathrm{BH}$, Zhu WB, Huang $\mathrm{YH}, \mathrm{Li} \mathrm{Y}, \mathrm{Yan} \mathrm{Q}$. An in vitro study of differentiation of hematopoietic cells to endothelial cells. Bone Marrow Res 2011; 846096. https://doi.org/10.1155/2011/846096.

10. Seurder D, Radrizzani M, Turchetto L, Lo Cicero V, Soncin S, Muzzarelli $\mathrm{S}$, et al. Combined delivery of bone marrow-derived mononuclear cells in chronic ischemic heart disease: rationale and study design. Clin Card 2013; 36(8): 435-441. https://doi.org/10.1002/clc.22148.

11. Kandala J, Upadhyay GA, Pokushalov E, Wu S, Drachman DE, Singh JP. Meta-analysis of stem cell therapy in chronic ischemic 
cardiomyopathy. Am J Card 2013; 112(2): 217-225. https://doi.org/10.1016/j.amjcard.2013.03.021.

12. Tsai TH, Lu CH, Wallace CG, Chang WN, Chen SF, Huang CR, et al. Erythropoietin improves long-term neurological outcome in acute ischemic stroke patients: a randomized, prospective, placebocontrolled clinical trial. Crit Care 2015; 19: 49. https://doi.org/10.1186/s13054-015-0761-8.

13. Ahmed SH, Sabry D, Noh O, Samir M. Potential proliferative effect of lipopolysaccharide preconditioning on human umbilical blood-derived endothelial cells. African Journal of Biotechnology 2015; 14(13): 11671173. https://doi.org/10.5897/AJB2014.14392.

14. Hur J, Yoon $\mathrm{CH}$, Kim HS, Choi JH, Kang HJ, Hwang KK, et al. Characterization of two types of endothelial progenitor cells and their different contributions to neovasculogenesis. Arterioscler Thromb Vasc Biol 2004; 24: 288-293. https://doi.org/10.1161/01.ATV.0000114236.77009.06.

15. Hristov M, Zernecke A, Bidzhekov K, Liehn EA, Shagdarsuren E, Ludwig $A$, et al. Importance of CXC chemokine receptor 2 in the homing of human peripheral blood endothelial progenitor cells to sites of arterial injury. Circ Res 2007; 100(4): 590-597. https://doi.org/10.1161/01.RES.0000259043.42571.68.

16. Beleslin-Cokic BB, Cokic VP, Yu X, Weksler BB, Schechter AN, Noguchi CT. Erythropoietin and hypoxia stimulate erythropoietin receptor and nitric oxide production by endothelial cells. Blood 2004; 104: 20732080. https://doi.org/10.1016/j.cyto.2011.01.015.

17. Zakharov YuM. Cytoprotective effects of erythropoietin. Clinical Nephrology 2009; (1): 16-21. Russian. https://elibrary.ry/item.asp?id=12993042.

18. Kang J, Yun JY, Hur J, Kang JA, Choi JI, Ko SB, et al. Erythropoietin priming improves the vasculogenic potential of G-CSF mobilized human peripheral blood mononuclear cells. Cardiovasc Res 2014; 104(1): 171-182. https://doi.org/10.1093/cvr/cvu180.

19. Bennis Y, Sarlon-Bartoli G, Guillet B, Lucas L, Pellegrini L, Velly L, et al. Priming of late endothelial progenitor cells with erythropoietin before transplantation requires the CD131 receptor subunit and enhances their angiogenic potential. J Thromb Haemost 2012; 10(9): 1914-1928. https://doi.org/10.1111/j.1538-7836.2012.04835.x.

\section{Authors:}

Alexander P. Lykov - MD, PhD, Senior Researcher, Laboratory of Cell Technologies of the Center of New Technologies, Meshalkin National Medical Research Center, Novosibirsk, Russia; Leading Researcher, Laboratory of Cell Technologies, Research Institute of Clinical and Experimental Lymphology - Branch of the Institute of Cytology and Genetics, Novosibirsk, Russia. http://orcid.org/0000-0003-4897-8676.

Olga V. Poveshchenko - MD, DSc, Head of the Laboratory of Cell Technologies of the Center of New Technologies, Meshalkin National Medical Research Center, Novosibirsk, Russia; Head of the Laboratory of Cell Technologies, Research Institute of Clinical and Experimental Lymphology - Branch of the Institute of Cytology and Genetics, Novosibirsk, Russia. http://orcid.org/0000-0001-9956-0056.

Alexander M. Cherniavsky - MD, DSc, Head of Center for Surgery of Aorta, Coronary and Peripheral Arteries, Meshalkin National Medical Research Center, Novosibirsk, Russia. http://orcid.org/0000-0001-9818-8678.

Alexei V. Fomichev - MD, PhD, Researcher, Center for Surgery of Aorta, Coronary and Peripheral Arteries, Meshalkin National Medical Research Center, Novosibirsk, Russia. http://orcid.org/0000-0001-8576-9617.

Maria A. Surovtseva - MD, PhD, Senior Researcher, Laboratory of Cell Technologies of the Center of New Technologies, Meshalkin National Medical Research Center, Novosibirsk, Russia; Senior Researcher, Laboratory of Cell Technologies, Research Institute of Clinical and Experimental Lymphology - Branch of the Institute of Cytology and Genetics, Novosibirsk, Russia. http://orcid.org/0000-0002-4752-988X.

Natalia A. Bondarenko - PhD, Senior Researcher, Laboratory of Cell Technologies of the Center of New Technologies, Meshalkin National Medical Research Center, Novosibirsk, Russia; Researcher, Laboratory of Cell Technologies, Research Institute of Clinical and Experimental
Lymphology - Branch of the Institute of Cytology and Genetics, Novosibirsk, Russia. http://orcid.org/0000-0002-8443-656X.

Irina I. Kim - PhD, Junior Researcher, Laboratory of Cell Technologies of the Center of New Technologies, Meshalkin National Medical Research Center, Novosibirsk, Russia; Researcher, Laboratory of Cell Technologies, Research Institute of Clinical and Experimental Lymphology - Branch of the Institute of Cytology and Genetics, Novosibirsk, Russia. http://orcid.org/0000-0002-7380-2763.

Yulia E. Kareva - MD, PhD, Cardiovascular Surgeon, Researcher, Center for Surgery of Aorta, Coronary and Peripheral Arteries, Meshalkin National Medical Research Center, Novosibirsk, Russia. http://orcid.org/0000-00027787-4692.

Alexandra R. Tarkova - MD, Postgraduate Student, Meshalkin National Medical Research Center, Novosibirsk, Russia. http://orcid.org/0000-00024291-6047. 